\title{
Process of Patients Telling Children about Newly Diagnosed Breast Cancer
}

\author{
Ikue Shiino ${ }^{*}$, Kumi Suzuki² \\ ${ }^{1}$ Yodogawa Christian Hospital Nursing, Osaka, Japan \\ ${ }^{2}$ Osaka Medical College, Faculty of Nursing, Osaka, Japan \\ Email: *a297114@ych.or.jp
}

How to cite this paper: Shiino, I. and Suzuki, K. (2020) Process of Patients Telling Children about Newly Diagnosed Breast Cancer. Open Journal of Nursing, 10, 598-612.

https://doi.org/10.4236/ojn.2020.106041

Received: April 29, 2020

Accepted: May 31, 2020

Published: June 3, 2020

Copyright $\odot 2020$ by author(s) and Scientific Research Publishing Inc. This work is licensed under the Creative Commons Attribution International License (CC BY 4.0). http://creativecommons.org/licenses/by/4.0/

\section{Open Access}

\begin{abstract}
Objective: This study aims to determine the process of patients with newly diagnosed breast cancer in Japan telling their children about the disease, and how they have thought about it after the diagnosis. Methods: Semi-structured interviews were conducted with 15 patients with newly diagnosed breast cancer who had 3- to 14-year-old children. Narratives of participants about how they told their children about the disease were analysed by a qualitative and descriptive study design using the Modified Grounded Theory Approach (M-GTA). Results: In the process by which patients with newly diagnosed breast cancer tell their children about the disease, participants were [Maintaining mental balance in the face of the threat of the cancer] after the breast cancer diagnosis, and used the "Facing the cancer through the relationship with the children" as the core category in the process. The participants had [Determined to tell the children about the disease], while [Being worried about the influence of cancer on the children], [Thinking about the benefits of not hiding the cancer], and [Feeling difficulty in communicating the diagnosis of cancer to their children]. They were [Encouraged to tell about the disease to the children] by people around them, and did tell the children that they had a "disease" or "cancer". The participants who told the children that they had the disease while [Determining the impact on the children] repeated the [Making herself look unconcerned] in the process. Those who told the children that they had cancer while [Determining the impact on the children] repeated [Talking openly about cancer and death] between parents and children. Conclusions: The participants came to face their own cancer by maintaining mental balance in the face of the threat of the cancer and telling their children about the disease. Nurses need to assist these patients to be able to deal openly with their children from the early stage of the diagnosis and solve problems by family members.
\end{abstract}




\section{Keywords}

Breast Cancer, Telling Children, Relationship with the Children, Family Support, Modified Grounded Theory Approach

\section{Introduction}

It is estimated that among patients newly diagnosed with cancer, every year approximately 56,000 of cancer patients in Japan have children under the age of 18, and that the number of children is approximately 87,000 . By type of cancer, breast cancer is the most common, accounting for $40.1 \%$ of all cancer diagnoses [1]. The number of patients diagnosed with breast cancer increases from the $30 \mathrm{~s}$ and peaks in the late $40 \mathrm{~s}$ [2]. Due to the recent tendency to marry later and the higher age of mothers giving birth to the first child (average age at birth of first child, 30.7 years) [3], it is expected that the number of breast cancer patients with children under 18 years old will increase. When a mother with children is diagnosed with breast cancer, the roles as a mother and the family relationships change due to the side effects of the breast cancer treatment, and it is difficult to adapt to the realities of the disease [4]. This makes it necessary for patient mothers to explain to their children the changes in their lives arising from the disease and treatment.

It is reported that telling the children about the disease enables patients to maintain the trust of children [5] [6], and also enables children to be prepared for what may occur during the treatment [4] [7] [8]. However, patients find it difficult to decide if, when, and how to tell the children [8] [9], and they wish to have access to support from medical professionals [6] [7] [8] [9]. It has been reported that posttraumatic stress symptoms may appear when a parent suffers from cancer, and that the later a child knows that the parent has cancer, the more serious the stress symptoms become [10]. Further, it has also been reported that the timing when patients who have been diagnosed with cancer tell their children about the disease commonly is late because of the impact of the diagnosis [10], and this suggests the necessity of providing professional support to these patients.

One reason for this is that for cancer patients, their family including the children, also play a significant role as caregivers in this situation [11], and it is also important to support the family. However, a literature review on how cancer patients tell their children about the disease has reported that there are only few studies that investigated the process of breast cancer patients telling their children about the disease [12]. To understand these issues better, this study aims to determine the process of the patients telling their children about the disease, and how they have thought about it after the diagnosis. Understanding the process and thoughts the patients have had may help us to obtain ideas for assisting breast cancer patients in their efforts to tell their children about the disease. 


\section{Methods}

\subsection{Research Design}

This study employed a qualitative and descriptive study design using the Modified Grounded Theory Approach (M-GTA) [13] to determine the process of breast cancer patients telling their children about the disease. The M-GTA is a method of analysis developed by Kinoshita [13]. This method combines a unique coding method based on the theoretical characteristics of the Grounded Theory Approach proposed by Glaser and Strauss in the 1960s. The M-GTA approach to generate a theory is reported as excellent in explaining and predicting human behaviour, and is suitable for studies that involve societal interactions where people interact directly, and for studies that investigate process-like phenomena [13]. As the purposes of this study are to understand the behaviors related to the interaction between breast cancer patients and their children, and determine the process-like phenomena where patients tell their children about the disease, we determined that the M-GTA would be a suitable approach.

\subsection{Definition of Terms}

Telling about the disease is defined as the act that breast cancer patients explain about the disease name, conditions, and treatment to their children, or the activity where patients explain about changes in appearance and physical functions due to the treatment, depending on the age of the child, and repeatedly explain that they have a "disease" or "cancer" in response to the reactions of the children.

\subsection{Subjects}

Potential subjects for the study were patients with newly diagnosed breast cancer who had children from 3 to 14 years of age, visiting general hospitals with breast surgery sections or breast clinics, diagnosed more than 6 months prior to the contact with the researcher, and having told their children about the disease. We decided the youngest age of children to be 3 years, the age at which children can understand explanations about changes in everyday life by parents even if they do not know the meaning of words like "cancer". The upper limit, 15 years old, was chosen as it is the upper limit of compulsory education in Japanese schools. Exclusion criteria are: 1) Patients diagnosed with metastasis or Stage IV advanced cancer when they were diagnosed with breast cancer; 2) Patients with clinically problematic mental health symptoms or mental illnesses; and 3) Patients who may experience difficulties when being interviewed due to physical symptoms as side effects of treatment.

\subsection{Date Collection}

Semi-structured interviews were conducted using an interview guide created by the researchers. After obtaining permission from patients to participate, interviews were recorded with an electronic recording device, and the statements were 
transcribed. The length of an interview was about 45 - 60 minutes per participant, and the number of interviews was, basically, once. Table 1 shows the details of the interview questions. The interview consisted of "thoughts at the time of the diagnosis of breast cancer", the "situation when thinking about telling the children about the disease", "details that the children were told", and "thoughts about the children after telling about the disease". We obtained information on the diagnosis, treatment history, age, and family structure from the medical records. The data collection period was from August of 2017 to March of 2018.

\subsection{Date Analysis}

The process of analysis using the M-GTA approach is as follows: determine the range of data and the theme of analysis; create analysis worksheets where the concept name, definition, concrete examples, theoretical notes for each concept are written in, which enable coding without intercepting the interview data and a thorough interpretation while assuming the viewpoint of the "researcher". Using the concept as the smallest unit of analysis, theoretical sampling and continuous comparative analysis are performed through concurrent reasoning and comprehensive thinking, while considering similar and opposite cases between concepts, to achieve theoretical saturation [13]. In this study, we decided on the focus of the analysis to be "patients with newly diagnosed breast cancer who had 3 to 14 -year-old children and who had told the children about the disease".

Table 1. Structure of the interview guide.

1) Feelings when patients were diagnosed with breast cancer

- What did you think about when you were diagnosed with breast cancer?

2) Situations where patients thought about telling their children about the disease

- When did you start thinking about telling your children about the disease?

- Before telling your children, did you make preparations beforehand such as consulting with someone?

- Did you have any problems in telling your children about the disease?

- What did you want your children to understand?

3) Situation when telling children

- At what timing, in what situation, and with what language did you tell your children about the disease? Please tell me specifically.

- Why did you choose the timing to tell your children about the disease?

- Did you pay special attention to something (child personality, age, developmental stage) when you told your children about the disease?

- Were you able to tell what you wanted to tell your children? Please tell us how you felt at that time.

4) Situation after telling the children about the disease

- Please tell me the reaction of your children when you told them. How did you feel and respond to that?

- How did you feel after telling your children? 
Further, the theme of the analysis was decided as "the process after the diagnosis to tell the children about the disease, including what the patients thought and relevant activities, how they told their children about the disease, and how they responded to their children". After collecting the data from participants, we selected one case with a rich narrative. After reading the narrative carefully, we interpreted the meanings of the parts related to the topic of the analysis generated a concept that faithfully represented the meaning, and created an analysis worksheet. From the second case onwards, we examined similar and opposite cases, and generated further concepts. After the analysis of all participant data, we generated categories, investigated the interrelationship between the categories, where the categories are located in the process of telling the children about the disease, and drew a result diagram. Using the result diagram, we generated a core category that includes the process of telling their children about the disease, and finally, created storylines to explain the result diagram.

\subsection{Trustworthiness}

We made every effort to ensure the trustworthiness of the qualitative research using the criteria of Shenton [14], and engaged in the analysis by adopting the M-GTA, which is suitable for studying process characteristics and has been established as a research method suited to enhance credibility. The study includes participants from two participating facilities to collect data from participants who met inclusion criteria according to the purpose of the study. One researcher performed all analyses on the data, under the instruction and supervision of a supervisor with M-GTA research experience, and the validity of the analysis was confirmed by the two researchers. For the result diagram and storyline, the consistency with the analyses was evaluated by researchers familiar with cancer nursing. To improve transferability, we describe the research facility, inclusion criteria of participants, number of participants, data collection method and period, and identify future issues. To improve dependability, we have described the process and implementation of the research design, data collection, and methods in detail.

\subsection{Ethical Approval}

This study was approved by the ethics review committees of Osaka Medical College (Approval No. Nursing-57 (2169)) and the ethics review committees of the participating facilities (No. 2017-019). The outline of the study including the purpose, significance, and methods, as well as and ethical considerations, such as voluntary participation, freedom of withdrawal, absence of advantages and disadvantages due to participation or refusal, protection of personal information, methods of data storage, management, and also the destruction of data and publication of the study results were all explained to the participants in writing and orally by the researchers. Participants expressed consent to participate in the study by signing an informed consent form. We proceeded with the interviews paying careful attention to the physical conditions and mental burden on the participants. 


\section{Results}

\subsection{Participant Characteristics}

Fifteen mothers fulfilled the inclusion criteria. Table 2 shows the demographics of the participants. The mean age was 40.1 years and the mean length of time from diagnosis to interview was 15.8 months. The total number of children of the participants was 21 and their mean age was 8.0 years. Seven participants reported that they had told their children that they had a "disease", and these children were mostly preschool ages, two of them told their children that they had "cancer" after having told they had a "disease", six had used the term "cancer", and two used different terms for telling brothers and sisters, "disease" or "cancer".

\subsection{Results of the Analysis}

Twenty-two concepts were generated and summarized into 9 categories, from which one core category was generated representing eight categories. We created a result diagram (Figure 1) that comprehensively represents the interrelationships

Table 2. Demographics of participants.

\begin{tabular}{|c|c|c|c|c|c|c|c|c|c|c|c|}
\hline & Age & $\begin{array}{l}\text { Postdiagnosis } \\
\text { month }\end{array}$ & Surgery & $\begin{array}{l}\text { Chemo } \\
\text { therapy }\end{array}$ & $\begin{array}{l}\text { Radio } \\
\text { therapy }\end{array}$ & $\begin{array}{c}\text { Endocrine } \\
\text { therapy }\end{array}$ & $\begin{array}{l}\text { Age of } \\
\text { child }\end{array}$ & Gender & Siblings & Spouse & Expression used \\
\hline A & $30 \mathrm{~s}$ & 15 & Partial $^{\star *}$ & No & Yes & Yes & 4 & Male & Yes & Yes & Disease \\
\hline B & $40 \mathrm{~s}$ & 17 & Partial & No & Yes & Yes & 13 & Male & Yes & No & Cancer \\
\hline $\mathrm{C}$ & $40 \mathrm{~s}$ & 22 & Total $^{*}$ & No & No & Yes & $\begin{array}{c}12 \\
7\end{array}$ & $\begin{array}{l}\text { Female } \\
\text { Male }\end{array}$ & Yes & Yes & $\begin{array}{c}\text { Cancer } \\
\text { Disease } \rightarrow \text { Cancer }\end{array}$ \\
\hline $\mathrm{D}$ & $30 \mathrm{~s}$ & 20 & Partial & Yes & Yes & Yes & 12 & Male & No & Yes & Cancer \\
\hline $\mathrm{E}$ & $30 \mathrm{~s}$ & 19 & Partial & No & Yes & Yes & $\begin{array}{l}7 \\
5\end{array}$ & $\begin{array}{l}\text { Female } \\
\text { Female }\end{array}$ & Yes & Yes & Disease \\
\hline $\mathrm{F}$ & $40 \mathrm{~s}$ & 9 & Partial & Yes & Yes & Yes & 4 & Female & No & Yes & Disease \\
\hline G & $40 \mathrm{~s}$ & 19 & Partial & Yes & No & Yes & 14 & Male & Yes & No & Cancer \\
\hline $\mathrm{H}$ & $40 \mathrm{~s}$ & 17 & Partial & $\mathrm{NAC}^{* * *}$ & Yes & Yes & $\begin{array}{c}10 \\
5\end{array}$ & $\begin{array}{l}\text { Female } \\
\text { Female }\end{array}$ & Yes & Yes & $\begin{array}{l}\text { Cancer } \\
\text { Disease }\end{array}$ \\
\hline I & $40 \mathrm{~s}$ & 8 & Total & No & Yes & Yes & 11 & Female & No & Yes & Cancer \\
\hline $\mathrm{J}$ & $40 \mathrm{~s}$ & 18 & Total & Yes & Yes & Yes & $\begin{array}{c}10 \\
8\end{array}$ & $\begin{array}{c}\text { Male } \\
\text { Female }\end{array}$ & Yes & Yes & Disease $\rightarrow$ Cancer \\
\hline K & $40 \mathrm{~s}$ & 11 & Total & Yes & Yes & Yes & 7 & Male & Yes & Yes & Disease \\
\hline $\mathrm{L}$ & $40 \mathrm{~s}$ & 24 & Partial & No & Yes & No & 14 & Female & No & Yes & Cancer \\
\hline M & $30 \mathrm{~s}$ & 18 & Total & NAC & No & No & 3 & Male & No & Yes & Disease \\
\hline $\mathrm{N}$ & $40 \mathrm{~s}$ & 9 & Total & Yes & No & Yes & $\begin{array}{c}10 \\
4\end{array}$ & $\begin{array}{c}\text { Male } \\
\text { Female }\end{array}$ & Yes & Yes & $\begin{array}{l}\text { Cancer } \\
\text { Disease }\end{array}$ \\
\hline $\mathrm{O}$ & $30 \mathrm{~s}$ & 11 & Partial & Yes & Yes & Yes & $\begin{array}{l}5 \\
3\end{array}$ & $\begin{array}{l}\text { Male } \\
\text { Male }\end{array}$ & Yes & Yes & Cancer \\
\hline
\end{tabular}

${ }^{\star}$ Surgery, Total: total mastectomy; ${ }^{*}$ Surgery, Partial: partial mastectomy; ${ }^{* *}$ Chemotherapy, NAC: Preoperative chemotherapy. 


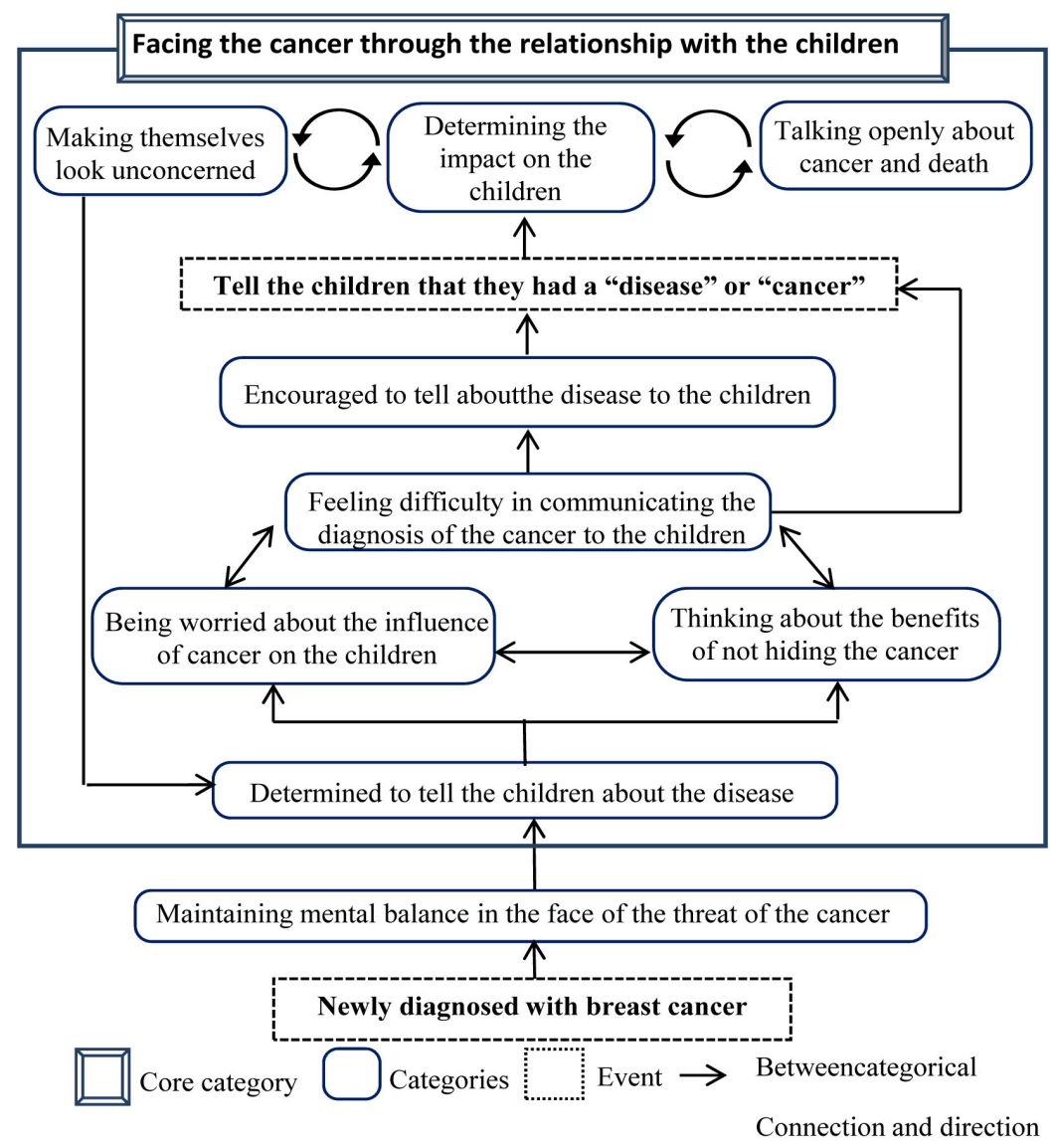

Figure 1. Process of patients telling children about newly diagnosed breast cancer.

among the one core category and the nine categories, and used the diagram to visualize the process of participants who had children from 3 to 14 years old telling their children about the disease.

Further, we created storylines that simplify the process of the result diagram. The core category is indicated as double angular brackets ("'), categories as square brackets ([ ]), and concepts are denoted with single quotation marks (' ').

\subsection{Storylines}

In the process of participants telling their children about the disease, participants were [Maintaining mental balance in the face of the threat of the cancer] after the breast cancer diagnosis, and then used the "Facing the cancer through the relationship with the children" as the core category in the process. The participants had [Determined to tell the children about the disease]. Further, after brooding on how to proceed, including [Being worried about the influence of cancer on the children], [Thinking about the benefits of nothiding the cancer], and [Feeling difficulty in communicating the diagnosis of the cancer to the children], the participants were [Encouraged to tell about the disease to the children] by people around them, and did tell the children that they had a "disease" or "cancer". The participants who told the children that they had a disease while [Determining the impact on the children] repeated the [Making themselves look 
unconcerned]. However, some participants [Determined to tell the children about the disease] again based on the stress response of the children, and told them about the disease by [Thinking about the benefits of not hiding the cancer] and [Feeling difficulty in communicating the diagnosis of the cancer to the children]. Those who told the children that they had cancer while [Determining the impact on the children] repeated [Talking openly about cancer and death] between parents and children.

\subsection{Definition of Core Category and Categories}

Table 3 shows the categories and concepts. Below is the list of the definitions and examples of the categories. Examples are indicated in italics, and the participant IDs are in round brackets ( ). "Facing the cancer through the relationship with the children" means that patients are trying to face their own cancer again through interactions with the children to tell them about the disease.

Table 3. Categories and concepts of the process by which patients with newly diagnosed breast cancer tell their children about the disease.

\begin{tabular}{|c|c|}
\hline Category & Concept \\
\hline \multirow{3}{*}{$\begin{array}{l}\text { Maintaining mental } \\
\text { balance in the face of } \\
\text { the threat of the cancer }\end{array}$} & Feeling distress by thinking about death by cancer \\
\hline & Thinking positively about the breast cancer \\
\hline & Trying not to be defeated by the threat of the cancer \\
\hline \multirow{2}{*}{$\begin{array}{l}\text { Determined to tell } \\
\text { the children } \\
\text { about the disease }\end{array}$} & $\begin{array}{l}\text { Thinking about the impact of the disease and treatment } \\
\text { on the lives of the children }\end{array}$ \\
\hline & Worried whether to say the disease or not \\
\hline \multirow{3}{*}{$\begin{array}{l}\text { Being worried about the } \\
\text { influence of cancer } \\
\text { on the children }\end{array}$} & Speculating about the psychological reaction of the children \\
\hline & Worrying about children feeling uneasy \\
\hline & $\begin{array}{l}\text { Feeling responsibility as unable to carry on with } \\
\text { the life of the children }\end{array}$ \\
\hline \multirow{3}{*}{$\begin{array}{l}\text { Thinking about the } \\
\text { benefits of not } \\
\text { hiding the cancer }\end{array}$} & Alleviate the own emotional burden \\
\hline & Obtaining support from the children \\
\hline & Estimating the impact on the parent-child relationship \\
\hline \multirow{3}{*}{$\begin{array}{l}\text { Feeling difficulty } \\
\text { in communicating } \\
\text { the diagnosis of } \\
\text { the cancer to the children }\end{array}$} & Speculating on the knowledge of children about cancer \\
\hline & $\begin{array}{l}\text { Cannot decide how to tell the children about the disease } \\
\text { without having them imagine death }\end{array}$ \\
\hline & $\begin{array}{l}\text { Thinking about how to tell the children about cancer without } \\
\text { other people finding out }\end{array}$ \\
\hline \multirow{2}{*}{$\begin{array}{l}\text { Encouraged to tell about } \\
\text { the disease to the children }\end{array}$} & Encouraged by family to tell children about the disease \\
\hline & Asking other people near the children for support \\
\hline \multirow{2}{*}{$\begin{array}{l}\text { Determining the } \\
\text { impact on the children }\end{array}$} & Intuiting a stress response of the children \\
\hline & Guessing whether the children would understand what was meant \\
\hline \multirow{2}{*}{$\begin{array}{l}\text { Making themselves look } \\
\text { unconcerned }\end{array}$} & Evading questions about the disease name by children \\
\hline & Relieved that there is no need to tell the children about cancer \\
\hline \multirow{2}{*}{$\begin{array}{c}\text { Talking openly } \\
\text { about cancer and death }\end{array}$} & Explain honestly according to child reactions \\
\hline & Assuring not going to die \\
\hline
\end{tabular}


[Maintaining mental balance in the face of the face of the threat of the cancer] means that patients have become aware of death after the cancer diagnosis, feeling mentally confused, and trying to calm their feelings when thinking about their children. Example for the category: I could not think positively after the diagnosis of cancer and thought that I would have to leave the children and die $(\mathrm{H})$; I felt somewhat relieved when I was informed that my cancer was in the early stage (I); I was in shock because I had thought death is inevitable for cancer patients $(\mathrm{A})$.

[Determined to tell the children about the disease] means that patients are worried about the impact of their cancer treatment on the everyday life of their children, and have decided to tell them about the disease as feeling it necessary to explain about the disease. Example for the category: I was grateful that the nurse asked me, "Are you going to tell your child about the disease?' If she had not asked me so, I would have been quite at a loss not knowing "What to say to my child" when I got home to my child (D); I have to tell them something because I will be hospitalized(J).

[Being worried about the influence of cancer on the children] means that patients are feeling agonized by imagining that telling about the disease may cause psychological distress for the children because they themselves experienced psychological distress after the cancer diagnosis. Example for the category: I thought it was harsh because my younger child, 14 years old, is a junior high school student, would not be able to accept the cancer, and has no knowledge of cancer $(\mathrm{G})$; I did not want my children to suffer from anxiety, and I wanted to behave as usual (K); I feel sorry if my children cannot associate with their friends as usual due to my disease $(\mathrm{M})$.

[Thinking about the benefits of not hiding the cancer] means that patients speculate about the benefits of honestly telling about the cancer to their children while thinking that hiding knowledge of the cancer from their children may cause stress for themselves and that parent-child relationships may be adversely affected. Example for the category: I think it will be harder to hide the cancer. If I have to continue to go to the hospital, I cannot keep it secret (D); I think I was able to do my best because my children stood by me... (O); I thought that the parent-child relationship would be strained if I was hiding the disease from my child (L).

[Feeling difficulty in communicating the diagnosis of the cancer to the children] means that patients are troubled and uncertain about how to explain about the disease, cancer, in order to prevent their children from thinking about death, by considering the age, personality, and the knowledge about cancer of the children. Example for the category: I do not mean to hide the name "breast cancer". I do not think my child would understand the meaning even if I told my child the name of the disease. He is still 5 years old. (A); (Children) may associate cancer with death. I had heard that in news programs and books. It is difficult to talk about cancer with children (D); The older brother is chatty, so I thought it would be troublesome if he says (name of disease) in kindergarten $(\mathrm{O})$. 
[Encouraged to tell about the disease to the children] means that patients are encouraged to tell about the disease or cancer, and treatment to the children by their spouse, friends, and school teachers, when patients consulted with them, and have determined to tell their children about the disease. Example for the category: I discussed with my husband or just asked my husband how to tell our children about the disease. His idea was the same as mine: I did not have to say the name of the disease (E); I was very encouraged by the teacher of the elementary school my child belongs to, saying, "If you need my help, please bring your child to me" although I do not know how much elementary school teachers know about stress responses $(\mathrm{F})$.

[Determining the impact on the children] means that patients have evaluated the impact of the disease on their children and how to perceive the disease from their responses after telling the children using the terms disease or cancer. Example for the category: My child was not feeling well and was accidentally wetting themselves. I thought it was due to stress (M); (I) Sometimes the daughter was upset saying, "I have to do something." Well, she having understood cancer, I guess she decided that mother would be all right, as far as she was concerned (I).

[Making themselves look unconcerned] means that patients are worried that their children would be suspicious about the disease while the mother is undergoing surgery or chemotherapy because it will affect the everyday life of the children, but patients feel relieved thinking that they were able to avoid using the term for the disease after the treatment. Example for the category: My son asked me, "What is cancer?' I replied that it is a disease name. I do not think he thinks it is the disease name for his mother (E); I think there is no need to tell my children about (disease name). Because I completed the course of treatment. Maybe, I do not need to tell them $(\mathrm{H})$.

[Talking openly about cancer and death] means that patients honestly answer the questions of children about the cancer and death, and discuss until they understand and accept the explanation. Example for the category: After all, I thought my children felt uneasy. I think I should have said to them, "Mom is okay" earlier because the surgery was over successfully (C); I told my children, "This is not a disease that makes people die". I wanted them to understand this $(\mathrm{H})$.

\section{Discussion}

\subsection{Facing the Cancer through the Relationship with the Children}

Before "Facing the cancer through the relationship with the children", participants had to think about death from the time of the shock of being diagnosed with breast cancer and needed to place things in perspective. Then, assuming that the cancer treatment they will undergo will have a significant impact on the life of their children, they may have thought that they have to explain it as cancer or disease to the children, and [Determined to tell the children about the disease]. 
The findings show that participants were [Being worried about the influence of cancer on the children], [Thinking about the benefits of not hiding the cancer], and [Feeling difficulty in communicating the diagnosis of the cancer to the children] to tell their children about the disease. Previous studies have reported that reasons parents gave for not telling children included not wanting to upset the children, and protect the life of the family and children [5] [8]. Further, in general, most people have the impression of cancer being "a scary disease that can lead to death with pain and distress" [15], and the participants themselves may have been worried about the disadvantages of hiding the cancer because they had experienced a shock at the time of the cancer diagnosis. At the same time, the participants feared that hiding the cancer would mean that they had to lie to their children, thinking that the parent-child relationships would be imperilled, and also considered that there were disadvantages in telling about the cancer. Ozawa [16] reported that children show various responses to their parents having cancer, but if parents communicate with children in open ways, this enables children to continue believing in others, and this will help in their development by learning to overcome difficulties while talking with and relying on their parents. This suggests that telling the children about the disease would promote open communication between parents and children, resulting in supporting the mental stability of both parents and children. Participants in this study were also worried about how to tell their children about the disease, depending on the age of their children, as has been reported in previous studies [7]-[9]. As it is reported that patients are worried that their families will suffer from shock or that their health condition will deteriorate if patients tell their families about the cancer [17], patients had difficulties in determining the way to tell about the disease that would be suitable to the age of their children without exposing the children to shock.

Participants who told that they had been diagnosed with the disease commonly had children of preschool age. It is reported that cognitive functions of children at this age are self-centered, and that children perceive things intuitively [18]. This suggests that the participants may have evaluated the cognitive functions of their children and thought that their children would not understand if explained by using a term like "cancer". Also, the result of "I feel relieved that there is no need to tell the children about the cancer" suggests that the participants themselves hesitated to use the term "cancer", and suggests that the participants faced a situation where they had to [Make themselves look unconcerned] by using the term "disease".

Participants who told children that they had cancer perceived how their children understood cancer by [Talking openly about cancer and death] while paying attention to the stress response of the children, and tried in various ways to interact with the children and explain the disease. The participants became aware that they needed to provide information which makes their children feel relieved through the parent child communication, and repeatedly had to stress that "they had to assure the children that they would not die". Communication between cancer patients and children is related to the stress response of the children [19], 
frank communication could eliminate suspicion that the children may have and alleviate the emotional burden which mothers feel in interacting with the children [7]. Overall, talking openly with children may strengthen a mutually trusting relationship between parents and children. Further, when parents talk openly about cancer and death, assuring the children that they will not die soon could be a key element in promoting the mental stability of the children.

\subsection{Suggestions for Helping Breast Cancer Patients Tell Their Children about the Disease}

Participants in this study made efforts to [Maintaining mental balance in the face of the threat of the cancer] after the cancer diagnosis. Showing the importance of stabilizing the psychological confusion of the parents as it is reported that telling about the disease may cause psychological distress in their children [10]. It is important for nurses to obtain information about the personality of children and support programs, as well as their age because the emotional and behavioral problems of children of cancer patients vary depending on their family structure, gender, and age [19]. For this reason, nurses need to intervene in case of a crisis to alleviate the impact of the diagnosis with cancer from the early stage of the diagnosis, and assist patients to be able to deal with their children through assessing information about the children at home.

The participants were worried about how to tell their children about the disease. However, it is reported that only $14.7 \%$ of nurses had the experience of having been asked about how to tell the children about the disease by cancer patients [20]. This suggests that support from nurses alone is insufficient. Therefore, encouraging the patients to tell their children about the disease offers an opportunity for patients to interact face to face with their children about this, contributing to the whole family.

\subsection{Limitations of and Issues to Be Addressed in Future Studies}

In this study, it was found that the process subsequent to the initial telling the children was different for mothers who used the term "disease" from the process following the use of the term "cancer", but factors related to the difference have not been found. Another limitation is the small number of samples, specifically when classifying the samples by the term they had used to tell the children. In total 15 patients participated in the study, and seven had used the term "disease", six "cancer", and two had used different terms for telling siblings, "disease" or "cancer". For the future, it will be necessary to collect more and more detailed data of breast cancer patients who used the terms "disease" or "cancer", and attempt to establish a detailed understanding to enable nurses to provide practical assistance.

\section{Conclusion}

In the process of participants telling their children about the disease, they thought about death due to the impact of having been diagnosed with breast cancer, but managed to stabilize the psychological confusion and determined to tell their 
children about the disease, thinking about the advantages and disadvantages of telling about the cancer, as well as how to tell about it, by telling the children about the disease calling it a "disease" or "cancer" supported by the whole family. After that, the participants who told that they had a disease tried to [Make themselves look unconcerned] by hiding the fact of the "cancer" diagnosis, and those who told the children that they had cancer repeated talking with their children. However, some participants who told that they had a disease thought about telling their children about cancer a second time when observing a stressed response of the children, and then told the children that they had cancer. This series of steps in the process implies that participants were "Facing the cancer through the relationship with the children". These findings suggest the importance for nurses to intervene in crisis that may arise with breast cancer patients, and assist these patients to be able to deal openly with their children from the early stage of the diagnosis.

\section{Acknowledgements}

We would like to thank the breast cancer patients for participating in this study interview. We also sincerely thank Dr. Junya Minohata, and Dr. Kazuyuki Wakita who helped recruit participants.

\section{Financial Support and Sponsorship}

This study was supported by the Cancer Research Grant of Osaka Cancer Society.

\section{Conflicts of Interest}

The authors declare no conflicts of interest regarding the publication of this paper.

\section{References}

[1] Inoue, I., Higashi, T., Iwamoto, M., Heiney, S.P., Tamaki, T., Osawa, K., et al. (2015) A National Profile of the Impact of Parental Cancer on Their Children in Japan. Cancer Epidemiology, 39, 838-841. https://doi.org/10.1016/j.canep.2015.10.005 https://www.sciencedirect.com/science/article/abs/pii/S1877782115002155

[2] Foundation for Promotion of Cancer Research $(1980,2013)$ Trends in Age-Specific Incidence Rate. Cancer Statistics in Japan, 17, 50-53.

https://ganjoho.jp/data/reg_stat/statistics/brochure/2017/cancer_statistics_2017stati stics_2017_fig_J.pdf

[3] Director-General for Statistics and Information Policy (2017) Ministry of Health, Labour and Welfare, Japan. Outline of Health, Labour and Welfare Statistics 2017. https://www.mhlw.go.jp/toukei/youran/aramashi/all.pdf

[4] Mazzotti, E., Serranò, F., Sebastiani, C. and Marchetti, P. (2012) Mother-Child Relationship as Perceived by Breast Cancer Women. Psychology, 3, 1027-1034. https://doi.org/10.4236/psych.2012.312154

[5] Barnes, J., Kroll, L., Burke, O., Lee, J., Jones, A. and Stein, A. (2000) Qualitative Interview Study of Communication between Parents and Children about Maternal 
Breast Cancer. BMJ, 321, 479-482. https://doi.org/10.1136/bmj.321.7259.479

[6] Turner, J., Clavarino, A., Yates, P., Hargraves, M. and Hausmann, S. (2007) Development of a Resource for Parents with Advanced Cancer: What Do Parents Want? Palliative and Supportive Care, 7, 135-145.

https://doi.org/10.1017/S1478951507070204

[7] Huang, X., O’Connor, M., Hu, Y., Gao, H. and Lee, S. (2016) Communication about Maternal Breast Cancer with Children: A Qualitative Study. Cancer Nursing, 40, 445-453. https://pubmed.ncbi.nlm.nih.gov/27922920 https://doi.org/10.1097/NCC.0000000000000456

[8] Kennedy, V.L. and Lloyd-Williams, M. (2009) Information and Communication When a Parent Has Advanced Cancer. Journal of Affective Disorders, 114, 149-155. https://pubmed.ncbi.nlm.nih.gov/18684513 https://doi.org/10.1016/j.jad.2008.06.022

[9] Semple, C.J. and McCaughan, E. (2013) Family Life When a Parent Is Diagnosed with Cancer: Impact of a Psychosocial Intervention for Young Children. European Journal of Cancer Care, 22, 219-231. https://pubmed.ncbi.nlm.nih.gov/23231498 https://doi.org/10.1111/ecc.12018

[10] Ozawa, M. (2014) Support for Children in Cancer Care. Ministry of Health, Labour and Welfare, Grant-in-Aid for Scientific Research, Cancer Clinical Research Project H23, Cancer Clinical-General-017, 2011-2013 General Research Report "Support for Children in Cancer Care", 1-9.

https://mhlw-grants.niph.go.jp/niph/search/NIDD00.do?resrchNum=201314015B

[11] Suzuki, K. and Watanabe, Y. (2016) Understanding the Family in Nursing Science, Theories for Understanding the Family: Theory of Family Development, Theory and Practice of Family Nursing. 4th Edition, Japan Nursing Association Press, Tokyo, 46-50.

[12] Shiino, I. and Suzuki, K. (2019) Cancer Patients Communicating with Their Children Regarding Their Illness: A Literature Review. Journal of Japanese Society of Cancer Nursing, 33, 21-28.

[13] Kinoshita, Y. (2003) Employing the Grounded Theory Approach: An Invitation to Qualitative Research. Kobundo, Tokyo.

[14] Shenton, A.K. (2004) Strategies for Ensuring Trustworthiness in Qualitative Research Projects. Education for Information, 22, 63-75.

https://pdfs.semanticscholar.org/cbe6/70d35e449ceed731466c316cd273032b28ca.pdf https://doi.org/10.3233/EFI-2004-22201

[15] Cabinet Office, Government of Japan (2014) Summary of Public Opinion Research on Cancer Control.

https://survey.gov-online.go.jp/h28/h28-gantaisaku/gairyaku.pdf

[16] Ozawa, M. (2014) Thoughts of Children of Cancer Patients (Stress Arising When Cancer Was Disclosed/Hidden). Nursing Today, 29, 16-20.

[17] Koshizuka, K., Kanda, K. and Fuzino, F. (2005) Caring of the Gynecological Cancer Patients for Their Families and Nursing Support. Bulletin of Faculty of Health Science, Okayama University Medical School, 16, 31-38.

http://ousar.lib.okayama-u.ac.jp/files/public/1/15181/20160527210306671210/016_1 _031_038.pdf

[18] Funashima, N. (2008) Human Development Sciences for Nursing. Igakushoin, Tokyo, 32-37.

[19] Kobayashi, M. and Matsushima, E. (2007) Liaison and Palliative Care: No. 31, for 
Mothers Diagnosed with Cancer, and Factors Related to Emotional and Behavioral Problems in Their Children. Psychiatry, 11, 395-398.

[20] Chazono, M. and Shindo, E. (2013) Nursing Education to Improve Skills in the Support of Cancer Patients of Childcare Age-Awareness of Nurses and Details of Support for Cancer Patients of Childcare Age to Be Able to Explain the Disease to Their Children. 2012 Keio University SFC Research Institute Project Auxiliary Report, 1-9. https://www.kri.sfc.keio.ac.jp/report/project/2012/4.chaen.pdf 